\title{
Abolition of methacholine induced bronchoconstriction by the hyperventilation of exercise or volition
}

\author{
S FREEDMAN, R LANE, M K GILLETT, A GUZ \\ From the Department of Medicine, Charing Cross and Westminster Medical School, London
}

\begin{abstract}
Total pulmonary resistance was measured from continuous records of flow and oesophageal pressure in five normal subjects on three separate days before and after inhalation of methacholine. The dose of methacholine produced, on average, a fivefold increase in airway resistance. Immediately after methacholine inhalation the subjects underwent a progressive exercise test on a cycle ergometer (day 1) or voluntary hyperventilation (day 2) or remained resting (day 3 ). On the first day during exercise pulmonary resistance fell rapidly to baseline levels within two to three minutes and remained there for the 10 minute duration of the exercise. On day 2 voluntary reproduction of the same level and pattern of ventilation as during exercise resulted in a similar fall of resistance. On the third day, when the subjects remained at rest, pulmonary resistance remained raised for 10 minutes. It is concluded that the bronchodilator effects of exercise can be explained by the increased ventilation rather than the exercise itself, but with much smaller tidal volumes than have previously been thought necessary to reduce drug induced bronchoconstriction.
\end{abstract}

\section{Introduction}

We have previously measured the sensation of breathing through a small added external resistance during exercise.' We wished to compare these results with the effects of a similar increase in internal pulmonary resistance induced by inhalation of methacholine, but to our surprise the resulting bronchoconstriction was so unstable during exercise that we were unable to do the planned experiments. We have investigated the mechanism underlying this instability. A single deep inspiration is known to reduce airway resistance in normal subjects ${ }^{2}$ and may reduce drug induced bronchoconstriction. ${ }^{34}$ To test whether the exercise itself or the accompanying increase in ventilation was responsible for this instability, we studied normal subjects after inhalation of methacholine, at rest, during exercise, and during voluntary hyperventilation.

Address for reprint requests: Dr S Freedman, Department of Medicine, Charing Cross and Westminster Medical School, London W6 8RF.

Accepted 18 May 1988

\section{Methods}

SUBJECTS AND MEASUREMENTS

The subjects were six normal men (aged 23-36 years), all of whom had normal spirometric values. None was asthmatic, although two had mild seasonal rhinitis.

Bronchoconstriction was induced by inhalation of methacholine chloride as described below, with the subject seated in a constant volume body plethysmograph (Fenyves and Gut). The degree of bronchoconstriction was controlled by making measurements of airway resistance (Raw) and specific conductance (sGaw) by standard techniques. Subjects panted at 2-3 $\mathrm{Hz}$ and loops were displayed on an $\mathrm{X}-\mathrm{Y}$ recorder. Measurements of slope were made on the inspiratory limbs of five pressure-flow loops at flow rates between 0 and $0.5 \mathrm{l} / \mathrm{s}$ and the mean value was taken.

To measure pulmonary resistance $\left(R_{L}\right)$, we used the method of Mead and Whittenberger. ${ }^{5}$ Oesophageal pressure was measured with a balloon tipped catheter by a standard technique. ${ }^{6}$ The catheter was connected to one side of a differential pressure transducer (Validyne), the other port of which was open to the atmosphere. The transducer was connected to a carrier amplifier (SE Ltd). Flow at the mouth was measured 
by means of a Fleisch pneumotachograph (No 3) connected to a second differential pressure transducer (Validyne). During exercise studies flow calibration was checked every minute. The flow signal was integrated by means of an analogue computer to give a volume signal. Flow and pressure measuring systems had a flat frequency response to frequencies beyond 10 Hz. End tidal gas tensions were measured with a mass spectrometer (Centronics). There was no apparatus for the subject to breathe through other than the pneumotachograph and mouthpiece.

All signals were recorded on a Mingograf ink jet recorder. Pressure, flow, and volume were also recorded on an FM tape recorder (Racal) for later analysis. The signals were replayed on to an $\mathrm{X}-\mathrm{Y}$ recorder to obtain pressure-flow traces as described by Mead and Whittenberger ${ }^{5}$ and as used during exercise by Stubbing et al. $^{7}$ Resistance (RL) was measured as the reciprocal of the slope of the pressure-flow trace measured on the inspiratory portion between the 0 and $0.5 \mathrm{l} / \mathrm{s}$ flow rates. The results include the resistance of the pneumotachograph $\left(0.12 \mathrm{~cm} \quad \mathrm{H}_{2} \mathrm{O} / 1 / \mathrm{s}\right.$ $(0.012 \mathrm{kPa} / \mathrm{l} / \mathrm{s}))$, which was considered small enough to make a subtraction unnecessary. Measurements are the average values from three or four breaths just before an inspiration to total lung capacity (TLC).

To validate the method we compared the values obtained from some randomly selected breaths with those obtained from the same breaths when the analysis was carried out by hand. The results were identical. Further validation was obtained from two other sources. Firstly, for one experiment in each subject simultaneous pressure-volume and flowvolume curves for breaths analysed by the MeadWhittenberger method were also analysed by the "isovolume" method ${ }^{8}$ to give "RisoV." Secondly, we compared RL obtained by the Mead-Whittenberger method with airway resistance measured in the body plethysmograph. These comparisons were between resting control values, obtained just before the administration of methacholine, and values at rest after the highest dose of methacholine.

EXPERIMENTAL PROTOCOL

Five subjects were studied on three occasions. Firstly, the oesophageal balloon was passed and resting flow, volume, and oesophageal pressure were recorded to obtain baseline RL. At the end of this period the subject was asked to breathe in to TLC so that the lung volume during the preceding breaths could be calculated. The subject was then seated in the body plethysmograph and inhaled methacholine chloride, starting with 6.25 or $12.5 \mathrm{mg} / \mathrm{ml}$ and proceeding to inhale doubling concentrations until a 4-6 fold increase in Raw was obtained. Methacholine was administered according to the protocol described by
Cockcroft et al, ${ }^{9}$ in which a Wright's nebuliser is driven $\overrightarrow{\vec{*}}$ by air from a cylinder at $71 / \mathrm{min}^{2}$ and the subject breathes from a close fitting rubber facemask for two $\frac{\bar{\sigma}}{5}$ minutes. This method delivered a total volume of $\overline{\bar{s}}$ about $0.26 \mathrm{ml}$ of solution. The subject then came out of $\overline{\mathrm{D}}$ the body plethysmograph and sat on the bicycle ergometer; further flow, volume, and oesophageal's pressure signals were recorded during quiet breathing. $\vec{O}$ After this one of three protocols was followed. On the first day the subject did 10-13 minutes of heavy $\vec{\sigma}^{\circ}$ exercise, beginning at 25 watts and increasing over the $\vec{F}$ next three minutes to 150 watts. For the next 7-10 minutes the workload was changed each minute. between 120,150 , and 180 watts according to the protocol adopted in our previous experiments on respiratory sensation ${ }^{1}$ for the sake of uniformity. Ato the end of each one minute period subjects were asked to breathe in to TLC, so that end expiratory lung $D$ volume relative to TLC could be determined 00 Measurements were made on three or four breaths immediately before this.

On the second day the subject sat on the bicycleo ergometer but did not turn the pedals. He was asked to reproduce the ventilation achieved during the exerciseo experiment. The tidal volume signal recorded durings the exercise experiment was replayed as one of twoo traces on an oscilloscope screen, the other being hiso current breathing pattern. He was asked to breathe so that the two traces were matched as closely as possible. $\overrightarrow{\overrightarrow{0}}$ Thus not only total ventilation but tidal volume and $\beta$ frequency were exactly copied. TLC was again produced voluntarily every minute. During this. experiment hypocapnia was prevented by the addition of carbon dioxide at the mouth, end tidal carbon dioxide tension $\left(\mathrm{PCO}_{2}\right)$ being kept constant at aboux $4 \cdot 7-5 \cdot 3 \mathrm{kPa}$.

On the third day the subject sat on the bicycle and breathed normally without any special instruction? save a maximal inspiration to TLC each minute. This control experiment was designed to test the duration of the induced bronchoconstriction in the absence of increased ventilation.

STATISTICAL ANALYSIS

Two methods of measuring resistance (plethys mograph and Mead-Whittenberger) were compared ${ }^{\omega}$ by the method of Bland and Altman. ${ }^{10}$ Group meane levels of $R L$ were compared between tests at $0,2,5$, ance 10 minutes after methacholine inhalation by a two waye analysis of variance as follows: (1) test type (three levels) and (2) time (four levels). Group mean levels of ventilation and tidal volume were compared between exercise and hyperventilation by a two way analysis of variance as follows: (1) test type (two levels) and (2) $\mathcal{R}$ time (11 levels). Group mean levels of RL and Risov were compared during exercise by a two way analysis 
of variance as follows: (1) measurement type (two levels) and (2) time (11 levels). Statistical significance was tested by Fisher's least significant difference method," which allows comparison of any two mean levels between variables, $\mathrm{p}<0.05$ being taken as indicating a significant difference.

\section{Results}

\section{Comparison of $R \mathrm{~L}$ and Raw}

Values of $R \mathbf{L}$ and Raw were compared at rest and immediately after the highest dose of methacholine. Raw was on average higher than RL. Before methacholine the mean difference was $0.315 \mathrm{~cm} \mathrm{H}_{2} \mathrm{O} / 1 / \mathrm{s}(\mathrm{n}=$ $18 ; 95 \%$ confidence limits from -0.148 to 0.778 ) and after methacholine the mean difference was $1.164 \mathrm{~cm}$ $\mathrm{H}_{2} \mathrm{O} / \mathrm{l} / \mathrm{s}(\mathrm{n}=14 ; 95 \%$ confidence limits 2.562 to $-1.758)$.

\section{Changes in RL with exercise and hyperventilation}

Individual values of $R_{L}$ are presented in table 1 . This shows that generally similar levels of $R_{L}$ were achieved after methacholine inhalation in any given subject on the three experimental days. Exercise and hyperventilation produced a similar pattern of fall in $R L$ and control values were generally maintained at a higher level for 10 minutes (fig 1). Analysis of variance showed no significant difference between exercise and hyperventilation but the rate of fall of $R_{L}$ between zero

$$
\mathrm{RL}
$$

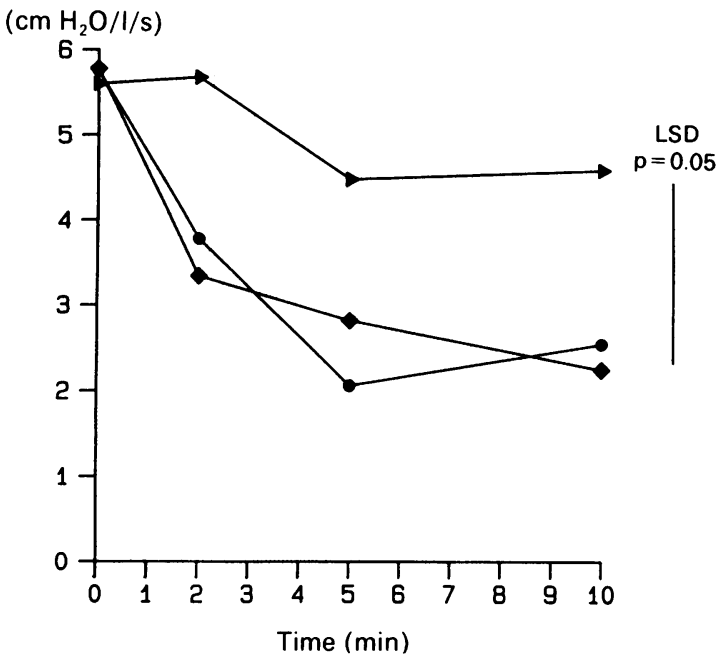

Fig 1 Mean values from five subjects for pulmonary resistance $\left(R_{L}\right)$ after methacholine inhalation during the exercise (๑), voluntary hyperventilation (४), and control ( ) experiments. The error bar shows significance at the $p=0.05$ level in terms of Fisher's least significant difference (LSD) statistic derived from an analysis of variance; this permits comparison of mean levels both within and between experiments. $\left(1 \mathrm{~cm} \mathrm{H}_{2} \mathrm{O} / \mathrm{l} / \mathrm{s}=0.1 \mathrm{kPa} / \mathrm{l} / \mathrm{s}\right.$.)
Table 1 Individual data on pulmonary resistance ( $R L)$ for all experiments

\begin{tabular}{|c|c|c|c|c|c|}
\hline \multirow[t]{2}{*}{$\begin{array}{l}\text { Subject } \\
\text { No }\end{array}$} & \multirow[t]{2}{*}{ Condition } & \multicolumn{4}{|c|}{$\begin{array}{l}\mathrm{RL}\left(\mathrm{cm} \mathrm{H}_{2} \mathrm{O} / \mathrm{l} / \mathrm{s}\right) \\
\text { Time after methacholine (min) }\end{array}$} \\
\hline & & 0 & 2 & 5 & 10 \\
\hline 1 & $\begin{array}{l}\text { Ex } \\
\text { HV } \\
\text { C }\end{array}$ & $\begin{array}{l}6 \cdot 3 \\
6 \cdot 7 \\
7 \cdot 1\end{array}$ & $\begin{array}{l}4 \cdot 4 \\
3 \cdot 9 \\
8 \cdot 2\end{array}$ & $\begin{array}{l}2 \cdot 1 \\
3 \cdot 2 \\
6 \cdot 4\end{array}$ & $\begin{array}{l}2 \cdot 0 \\
1 \cdot 7 \\
4 \cdot 9\end{array}$ \\
\hline 2 & $\begin{array}{l}\text { Ex } \\
\text { HV } \\
\text { C }\end{array}$ & $\begin{array}{l}6 \cdot 8 \\
6 \cdot 1 \\
7 \cdot 3\end{array}$ & $\begin{array}{r}3 \cdot 3 \\
3 \cdot 1 \\
10 \cdot 1\end{array}$ & $\begin{array}{l}1.9 \\
1.6 \\
7.5\end{array}$ & $\begin{array}{l}1.9 \\
1.2 \\
7.9\end{array}$ \\
\hline 3 & $\begin{array}{l}\text { Ex } \\
\text { HV } \\
\text { C }\end{array}$ & $\begin{array}{l}5 \cdot 0 \\
6 \cdot 0 \\
3 \cdot 8\end{array}$ & $\begin{array}{l}2 \cdot 5 \\
3 \cdot 3 \\
3 \cdot 7\end{array}$ & $\begin{array}{l}1 \cdot 7 \\
3 \cdot 2 \\
2 \cdot 8\end{array}$ & $\begin{array}{l}2 \cdot 3 \\
2 \cdot 4 \\
2 \cdot 9\end{array}$ \\
\hline 4 & $\begin{array}{l}\text { Ex } \\
\text { HV } \\
\text { C }\end{array}$ & $\begin{array}{l}6 \cdot 5 \\
6 \cdot 7 \\
5 \cdot 2\end{array}$ & $\begin{array}{l}5 \cdot 3 \\
3 \cdot 9 \\
2 \cdot 3\end{array}$ & $\begin{array}{l}2 \cdot 4 \\
4 \cdot 7 \\
2 \cdot 5\end{array}$ & $\begin{array}{l}3 \cdot 1 \\
4 \cdot 2 \\
2 \cdot 6\end{array}$ \\
\hline 5 & $\begin{array}{l}\text { Ex } \\
\text { HV } \\
\text { C }\end{array}$ & $\begin{array}{l}4 \cdot 2 \\
3 \cdot 4 \\
4 \cdot 6\end{array}$ & $\begin{array}{l}3 \cdot 4 \\
2 \cdot 5 \\
4 \cdot 1\end{array}$ & $\begin{array}{l}2 \cdot 2 \\
1 \cdot 4 \\
3 \cdot 2\end{array}$ & $\begin{array}{l}3 \cdot 4 \\
1 \cdot 7 \\
4 \cdot 6\end{array}$ \\
\hline
\end{tabular}

Ex-exercise; $\mathrm{HV}$-hyperventilation; $\mathrm{C}$-control.

Conversion: Traditional to SI units- $\mathrm{RL}_{\mathrm{L}} 1 \mathrm{~cm} \mathrm{H}_{2} \mathrm{O} / \mathrm{l} / \mathrm{s}=0.1$ $\mathrm{kPa} / \mathrm{l} / \mathrm{s}$.

and five minutes was greater for exercise and hyperventilation than for the control (Fisher's least significant difference $=1.009 \mathrm{~cm} \mathrm{H}_{2} \mathrm{O} / \mathrm{l} / \mathrm{s}$ at $5 \%$ level). When differences at specific times were compared, $\mathrm{RL}_{\mathbf{L}}$ during exercise and hyperventilation was significantly lower than control values at all times except for exercise at two minutes and hyperventilation at five minutes, which just failed to reach the $5 \%$ level of significance (Fisher's least significant difference $=$ $2 \cdot 12 \mathrm{~cm} \mathrm{H} / \mathrm{O} / \mathrm{l} / \mathrm{s}$ ). The two subjects with rhinitis (Nos 1 and 2) were similar to the other three subjects.

Ventilation during exercise or voluntary hyperventilation averaged about $50 \mathrm{l} / \mathrm{min}$ with tidal volumes ranging from 1.3 to 2.51 (fig 2). All subjects copied their exercise ventilation and tidal volume adequately during voluntary hyperventilation. There were no significant differences between exercise and hyperventilation (Fisher's least significant difference $=0.3771$ for tidal volume and $8.9851 / \mathrm{min}$ for ventilation, at the $5 \%$ level).

Four subjects had an increase in functional residual capacity immediately after methacholine. The end expiratory level fell during exercise in four of the five subjects, by $0.3-0.7$ litres on average over the final nine minutes. If the resistance data are expressed as specific resistance ( $R_{L} \times$ end expiratory lung volume), the pattern of changes shown in figure 1 and the significance of the differences are unaltered.

There was a progressive increase in tidal volume and end inspiratory lung volume (tidal volume as a fraction of inspiratory capacity) in all subjects (table 2).

The mean values of RisoV and RL during exercise (see under "Methods") are shown in figure 3. RisoV was at all times higher than RL but the difference failed 
to reach significance with analysis of variance (Fisher's least significant difference $=1.32 \mathrm{~cm} \mathrm{H}_{2} \mathrm{O} / 1 / \mathrm{s}$ at the $5 \%$ level) and the pattern of change with time was identical.

\section{Discussion}

Our study shows that methacholine induced bron-

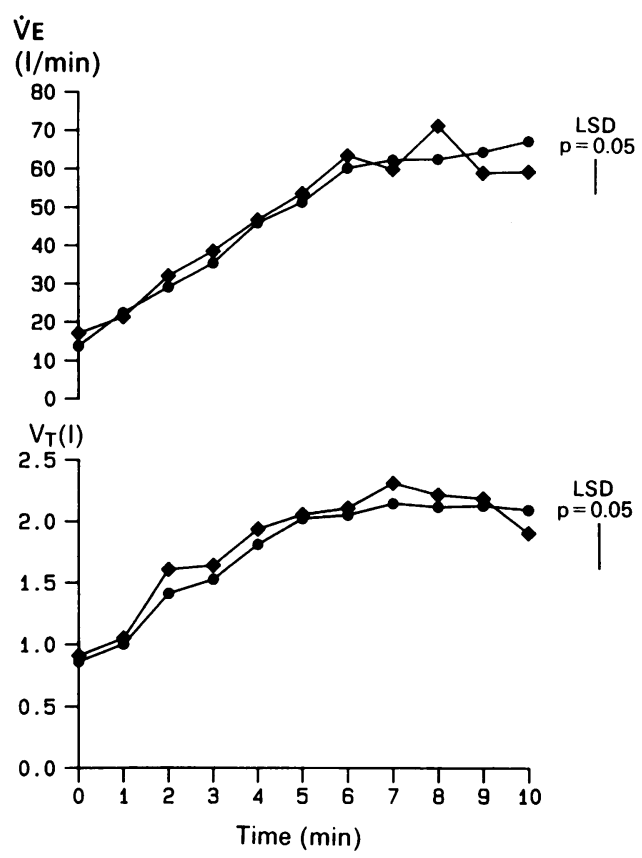

Fig 2 Mean values ( $n=5)$ of ventilation ( $\dot{\mathrm{V}}_{\mathrm{E}}$ ) and tidal volume (VT) after methacholine inhalation during exercise (๑) and voluntary hyperventilation $(\diamond)$. Error bars show significance at the $p=0.05$ level in terms of Fisher's least significant difference ( $L S D$ ) statistic derived from an analysis of variance.

Table 2 Changes in tidal volume and end inspiratory lung volumes during the exercise experiments

\begin{tabular}{|c|c|c|c|c|c|}
\hline \multirow{2}{*}{$\begin{array}{l}\text { Subject } \\
\text { No }\end{array}$} & & \multicolumn{4}{|c|}{ Time after methacholine (min) } \\
\hline & & 0 & 2 & 5 & 10 \\
\hline 1 & $\begin{array}{l}\text { VT } \\
\text { VT/IC\% }\end{array}$ & $\begin{array}{l}1.25 \\
66\end{array}$ & $\begin{array}{l}1 \cdot 5 \\
60\end{array}$ & $\begin{array}{l}2 \cdot 3 \\
75\end{array}$ & $\begin{array}{l}2 \cdot 1 \\
70\end{array}$ \\
\hline 2 & $\begin{array}{l}\text { VT } \\
\text { VT/IC\% }\end{array}$ & $\begin{array}{l}0.83 \\
27\end{array}$ & $\begin{array}{l}2 \cdot 1 \\
51\end{array}$ & $\begin{array}{l}2 \cdot 5 \\
69\end{array}$ & $\begin{array}{l}2 \cdot 5 \\
69\end{array}$ \\
\hline 3 & $\begin{array}{l}\text { VT } \\
\text { VT/IC\% }\end{array}$ & $\begin{array}{l}0.8 \\
40\end{array}$ & $\begin{array}{l}1 \cdot 3 \\
54\end{array}$ & $\begin{array}{l}1.85 \\
74\end{array}$ & $\begin{array}{l}1 \cdot 75 \\
71\end{array}$ \\
\hline 4 & $\begin{array}{l}\text { VT } \\
\text { VT/IC\% }\end{array}$ & $\begin{array}{l}0.73 \\
27\end{array}$ & $\begin{array}{l}1 \cdot 3 \\
36\end{array}$ & $\begin{array}{l}2.0 \\
57\end{array}$ & $\begin{array}{l}2 \cdot 3 \\
51\end{array}$ \\
\hline 5 & $\begin{array}{l}\text { VT } \\
\text { VT } / \mathbf{I C} \%\end{array}$ & $\begin{array}{l}0 \cdot 7 \\
39\end{array}$ & $\begin{array}{l}1.0 \\
55\end{array}$ & $\begin{array}{l}1 \cdot 5 \\
74\end{array}$ & $\begin{array}{l}1 \cdot 8 \\
77\end{array}$ \\
\hline
\end{tabular}

VT-tidal volume in litres; $\mathrm{VT} / \mathrm{IC} \%$-tidal volume as percentage of inspiratory capacity.

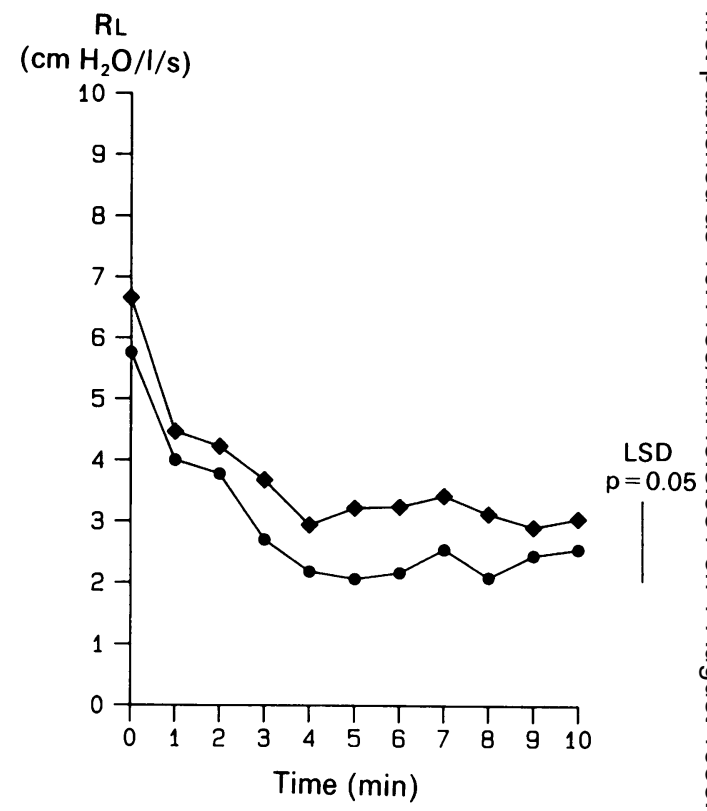

Fig 3 Mean levels $(n=5)$ of pulmonary resistance $(\mathrm{RL})$ during exercise after methacholine inhalation; comparison of resistance calculated by the method of Mead and

Whittenberger $^{5}(\bullet)$ and that of Cook et al $(\bullet)$. The error bar shows significance at the $p=0.05$ level in terms of

Fisher's least significant difference ( $L S D$ ) statistic derived from an analysis of variance. $\left(1 \mathrm{~cm} \mathrm{H} \mathrm{H}_{2} \mathrm{O} / \mathrm{l} / \mathrm{s}=0.1 \mathrm{kPa} / \mathrm{l} / \mathrm{s}\right.$. $)$

choconstriction is rapidly reversed by exercise, and apparently the increased ventilation accompanying exercise rather than the exercise itself is responsible응 From previous work in this laboratory ${ }^{12}$ and else $x$ where $^{13}$ we would have expected that increases in? pulmonary resistance induced by methacholine, of the magnitude we observed, would remain stable for about 25 minutes in the absence of any intervention.

It is important to determine that these changes in resistance were measuring a change in bronchiat dimensions and were not an artefact associated with‥ the increased ventilation. We have no independent means of assessing the validity of our measurements during exercise but there is strong evidence that they were not artefactual. The Mead-Whittenbergerw method gave results that were consistently slightly? lower than the results from the body plethysmographo whereas they might have been expected to be higher measuring as they do total pulmonary resistance as ${ }^{4}$ opposed to airway resistance in the plethysmograph. ${ }^{140}$ Moreover, measuring resistance during exercise by $\frac{2}{0}$ different method (RIsoV) gave slightly higher values? than the Mead-Whittenberger method, but the pattern of change during the course of an experiment was identical with the two methods. Thus we may haves 
consistently slightly underestimated $R_{L}$ but the pattern of change, with a fall during exercise and hyperventilation, is likely to be accurate. Theoretical considerations and measurements in man suggest that increased ventilation and flow would cause an artefactual rise in resistance rather than a fall. ${ }^{15}$

So that we could check the lung volumes at which our subjects were breathing, our protocol required them to breathe in to TLC every minute. This of itself could, and indeed did, lower pulmonary resistance. It could not, however, have been the entire explanation of our results because we followed the same protocol in control experiments, in which resistance did not fall in four subjects when measured on breaths immediately before an inspiration to TLC.

Changes in lung volume must also be considered as a factor relevant to changes in pulmonary resistance. End expiratory levels fell during exercise and voluntary hyperventilation in four subjects, by 0.3 to 0.7 litres. This would be expected to increase resistance rather than lower it. Ding et al $^{16}$ have recently shown that, when the airways of normal subjects are maximally constricted by methacholine, a fall in FRC of 0.51 produces an increase in pulmonary resistance. Thus the lung volume changes in our experiments could not be responsible for the reductions in pulmonary resistance during exercise or voluntary hyperventilation.

A deep inspiration has been shown to reduce drug induced bronchoconstriction in normal ${ }^{34}$ and asthmatic subjects. ${ }^{317-20}$ There are few data to indicate how deep an inspiration must be to achieve this effect, though Orehek et $a l^{18}$ suggested that an inspiration of at least $60 \%$ of inspiratory capacity was necessary to achieve a worthwhile fall in resistance. Our data (table 2), however, show that four of our five subjects did not achieve breaths of this size until more than two minutes of exercise had elapsed, whereas on average $62 \%$ of the total fall in resistance had occurred in this time. This suggests that repetitive smaller breaths can achieve the same effect as a single full inspiration. The mechanism by which a voluntary deep inspiration causes bronchodilatation has not been established, but Burns et $a{ }^{P^{1}}$ have produced strong evidence that it is a purely mechanical effect, related to the difference in pressure-volume hysteresis between lung tissue and airways. Fisher $e t a l^{22}$ have shown that the effect is present after drug induced bronchoconstriction in diabetic patients with autonomic neuropathy, suggesting that it is not a vagal reflex; but Glanville $e t a l^{3}$ found no such effect in patients after heart-lung transplantation, where the lungs are effectively denervated.

Results similar to ours (obtained by the same methods) were found in asthmatic subjects by Stirling et al, ${ }^{24}$ histamine producing little or no bronchocon- striction when inhaled during exercise or voluntary hyperventilation in doses that produced big increases in $R L$ at rest. Warren et al ${ }^{s}$ showed a fall in an index of pulmonary resistance during exercise in non-asthmatic subjects, which they attributed to a decrease in vagal tone as it was abolished by ipratropium inhalation but not by propranolol. Their baseline values, however, were very different as a result of inhalation of these drugs with their opposing pharmacological actions. It would appear from our results and those of Stirling $e t a l^{4}$ that, whatever the mechanism, it is not dependent on exercise as such and is probably therefore independent of changes in sympathetic tone and in circulating catecholamine concentrations during exercise.

Finally, whatever the underlying mechanism, we may speculate on a biological role for deep inspiration, voluntary or otherwise, as a way of diminishing airway resistance when the demand for ventilation is increased.

We thank Dr K MacRae, reader in medical statistics, Charing Cross and Westminster Medical School, for statistical advice.

\section{References}

1 Lane $\mathrm{R}$, Adams L, Guz A. Is low-level respiratory resistive loading during exercise perceived as breathlessness? Clin Sci 1987;73:627-34.

2 Nadel JA, Tierney DF. Effect of a previous deep inspiration on airway resistance in man. $J$ Appl Physiol 1961;16:717-9.

3 Fish JE, Ankin MG, Kelly JF, Peterman VI. Regulation of bronchomotor tone by lung inflation in asthmatic and non-asthmatic subjects. $J$ Appl Physiol 1981;50:1079-86.

4 Parham WM, Shephard RH, Norman PS, Fish JE. Analysis of time course and magnitude of lung inflation effects on airway tone: relation to airway reactivity. $\mathrm{Am}$ Rev Respir Dis 1983;128:240-5.

5 Mead J, Whittenberger JL. Physical properties of human lungs measured during spontaneous respiration. $J$ Appl Physiol 1953;5:779-96.

6 Milic-Emili J, Mead J, Turner JM, Glauser EM. Improved technique for estimating pleural pressure from oesophageal balloons. $J$ Appl Physiol 1964;19:207-11.

7 Stubbing DG, Pengelly LD, Morse JLC, Jones NL. Pulmonary mechanics during exercise in normal males. J Appl Physiol 1980;49:506-10.

8 Cook CD, Sutherland JM, Segal S, et al. Studies of respiratory physiology in the newborn infant. III. Measurements of mechanics of respiration. J Clin Invest 1957;36:440-8.

9 Cockroft DW, Killian DN, Mellon JJA, Hargreave FE. Bronchial reactivity to inhaled histamine: a method and clinical survey. Clin Allergy 1977;7:235-43.

10 Bland JH, Altman DG. Statistical methods for assessing 
agreement between two methods of clinical measurement. Lancet 1986;i:307-10.

11 Fisher RA. The design of experiments. London: Oliver and Boyd, 1935.

12 Chung KF, Snashall PD. Effect of prior bronchoconstriction on the airway response to histamine in normal subjects. Thorax 1984;39:40-5.

13 Hardy CC, Bradding P, Robinson C, Holgate ST. The combined effect of two pairs of mediators, adenosine with methacholine and prostaglandin $D_{2}$ with histamine, on airway calibre in asthma. Clin Sci 1986;71:385-92.

14 Marshall R, Du Bois AB. The measurement of the viscous resistance of the lung tissues in normal man. Clin Sci 1956;15:161-70.

15 Clement J, Bobbaers H, van de Woestijne KP. Influence of flow amplitude on pulmonary resistance determined near zero flow. Respir Physiol 1980;40:61-9.

16 Ding DJ, Martin JG, Macklem PT. Effects of lung volume on maximal methacholine-induced bronchoconstriction in normal humans. J Appl Physiol 1987;62:1324-30.

17 Fish JE, Peterman VI, Cugell DW. Effect of deep inspiration on airway conductance in subjects with allergic rhinitis and allergic asthma. $J$ Allergy Clin Immunol 1977;60:41-6.

18 Orehek J, Charpin D, Velardocchio JM, Grimaud C. Bronchomotor effect of bronchoconstriction-induced deep inspirations in asthmatics. Am Rev Respir Dis 1980;121:297-305.

19 Orehek J, Nicoli MM, Delpierre S, Beaupre A. Influence of the previous deep inspiration on the spirometric 흠 measurement of provoked bronchoconstriction in $\bar{G}$ asthma. Am Rev Respir Dis 1981;123:269-72.

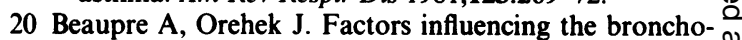
dilator effect of a deep inspiration in asthmatic patients $\mathrm{cs}$ with provoked bronchoconstriction. Thorax 1982; $\overrightarrow{0}$ 37:124-8.

21 Burns CB, Taylor WR, Ingram RH Jr. Effects of deep $\overrightarrow{\vec{\omega}}$ inhalation in asthma: relative airway and parenchymal hysteresis. J Appl Physiol 1985;59:1590-6.

22 Fisher BM, Dorward AJ, Thomson NC, Frier BM. Diabetic autonomic neuropathy and airway responses $\omega$ to deep inspiration [Abstract]. Clin Sci 1987;16 (suppl): 17P.

23 Glanville AR, Yeend RA, Theodore J, Robin ED. Effect of single respiratory manoeuvres on specific airway conductance in heart-lung transplant recipients. Clin Sci 1988;74:311-7.

24 Stirling DR, Cotton DJ, Graham BL, Hodgson WC, Cockroft DW, Dosman JL. Characteristics of airway tone during exercise in patients with asthma. $J$ Appl $\vec{O}$ Physiol 1983;54:934-42.

25 Warren JB, Jennings SJ, Clark TJH. Effect of adrenergic and vagal blockade on the normal human airway response to exercise. Clin Sci 1984;66:79-85. 